\title{
Effects of propofol on damage of rat intestinal epithelial cells induced by heat stress and lipopolysaccharides
}

\author{
J. Tang ${ }^{1 *}$, Y. Jiang ${ }^{1 *}$, Y. Tang ${ }^{2}$, B. Chen ${ }^{2}$, X. Sun ${ }^{3}$, L. Su ${ }^{2}$ and Z. Liu $^{2}$ \\ ${ }^{1}$ Department of Anesthesia, Nanfang Hospital, Southern Medical University, Guangzhou, China \\ ${ }^{2}$ Department of Intensive Care Unit, Guangzhou General Hospital of Guangzhou Military Command, Guangzhou, China \\ ${ }^{3}$ Laboratory of Traditional Chinese Medicine Syndrome, School of Traditional Chinese Medicine, \\ Southern Medical University, Guangzhou, China
}

\begin{abstract}
Gut-derived endotoxin and pathogenic bacteria have been proposed as important causative factors of morbidity and death during heat stroke. However, it is still unclear what kind of damage is induced by heat stress. In this study, the rat intestinal epithelial cell line (IEC-6) was treated with heat stress or a combination of heat stress and lipopolysaccharide (LPS). In addition, propofol, which plays an important role in anti-inflammation and organ protection, was applied to study its effects on cellular viability and apoptosis. Heat stress, LPS, or heat stress combined with LPS stimulation can all cause intestinal epithelial cell damage, including early apoptosis and subsequent necrosis. However, propofol can alleviate injuries caused by heat stress, LPS, or the combination of heat stress and LPS. Interestingly, propofol can only mitigate LPS-induced intestinal epithelial cell apoptosis, and has no protective role in heat-stress-induced apoptosis. This study developed a model that can mimic the intestinal heat stress environment. It demonstrates the effects on intestinal epithelial cell damage, and indicated that propofol could be used as a therapeutic drug for the treatment of heat-stress-induced intestinal injuries.
\end{abstract}

Key words: Propofol; Heat stress; Lipopolysaccharides; Apoptosis; Intestinal epithelial cells

\section{Introduction}

Heat stroke is a life-threatening condition in which the core body temperature rises rapidly to $40^{\circ} \mathrm{C}$ or higher and the body's heat-regulating mechanism breaks down. Moreover, heat stroke causes abnormalities in the central nervous system such as delirium, convulsions, and coma after exposure to a high ambient temperature (classic or non-exertional heat stroke) or strenuous exercise (exertional heat stroke). Current knowledge on heat stroke suggests that the pathophysiological consequence of heat stroke may not be due to an immediate effect of exposure to heat but may be a result of the systemic inflammatory response that follows thermal injury. Despite adequate lowering of the body temperature and intensive care support, heat stroke can often lead to multiple organ dysfunction syndrome (MODS) and death in these patients (1-3).

The gut contains a large number of the bacteria and endotoxins or lipopolysaccharides (LPS) in the body.
Gut-derived endotoxin and pathogenic bacteria have been proposed as important causative factors of morbidity and death during clinically relevant stresses such as heat stroke $(4,5)$, sepsis $(6)$, burn injury $(7,8)$, and ischemiareperfusion injury (9), as well as in critically ill patients (10). A number of studies on pathological examination of the small intestine reveal that lesions in this organ are common, and endotoxemia is present during heat stroke (11-15).

Intestinal epithelial cells are key components of the intestinal mucosal barrier. Damages to these cells will increase the permeability of the intestinal mucosal barrier, leading to increased gut-derived bacterial endotoxin translocation. In the process of heat stress or severe heat stroke, intestinal epithelial cells are attacked by environmental heat. The cells are also stimulated by intestinal bacteria and bacterial LPS. However, the type of damage induced by these stimuli on intestinal epithelial

Correspondence: Z. Liu, Department of Intensive Care Unit, Guangzhou General Hospital of Guangzhou Military Command, Guangzhou, China. Fax: +86-20-3665-5909. E-mail: serpentking@sina.com

${ }^{*}$ These authors contributed equally to this study.

Received November 5, 2012. Accepted April 19, 2013. First published online June 6, 2013. 
cells is still unclear. The first objective of the present study was to detect damage characteristics of intestinal epithelial cells under the combined stimuli of heat stress and LPS.

Propofol is an intravenous general anesthetic drug and is widely used in the induction and maintenance of anesthesia and sedation in intensive care units and for patients who need mechanical ventilation. Recent studies have shown that, in addition to the anesthetic effects, propofol also plays an important role in anti-inflammation and organ protection. For example, propofol can reduce the production of proinflammatory cytokines, alter the production of nitric oxide (16), and inhibit neutrophil function, leading to alleviation of the inflammatory response (17). Propofol can also regulate platelet aggregation $(18,19)$ and activate endogenous organ protection against hypoxic and ischemic injury (20). Our previous studies suggest that the intestinal inflammatory reaction plays an important role in intestinal injury during animal heat stroke (15). In view of the anti-inflammatory and organ-protective functions of propofol, the second purpose of this study was to detect the probable protective role of propofol in heat-stress-induced intestinal epithelial cell injury.

In this study, we developed an in vitro microenvironment for heat-stressed intestinal epithelial cells and investigated the injuries caused by heat stress and LPS. We also studied the effects of propofol on cellular injuries. These results would help to further understand the mechanisms of endotoxin translocation caused by intestinal barrier dysfunction during intestinal heat stress and provide potential therapy.

\section{Material and Methods}

Treatment of cells with heat stress, LPS, and propofol Rat IEC-6 cells (provided by Southern Medical University, China) were cultured in Dulbecco's modified Eagle's medium (DMEM) containing 5\% fetal bovine serum. Cells were passaged using ethylenediaminetetraacetic acid (EDTA)-trypsin to reach $80-90 \%$ confluence. After two passages, the cells were divided into the following groups: control, heat stress (HS), LPS (Sigma, USA) treatment, propofol (Sigma) treatment $(P), H S+L P S, H S+P$, LPS $+P$, and HS + LPS $+P$.

For heat stress, the medium of cells at $70 \%$ confluence was replaced with serum-free DMEM and incubated at $43^{\circ} \mathrm{C}$ for $1 \mathrm{~h}$. Subsequently, cells were incubated under normal conditions $\left(37^{\circ} \mathrm{C}\right.$ and $\left.5 \% \mathrm{CO}_{2}\right)$ for $23 \mathrm{~h}$. For LPS stimulation, cells were cultured in serum-free DMEM supplemented with $1 \mu \mathrm{g} / \mathrm{mL}$ LPS for $24 \mathrm{~h}$ under normal conditions. For HS + LPS, $1 \mu \mathrm{g} / \mathrm{mL}$ LPS was added to the cells, followed by $1 \mathrm{~h}$ of heat stress at $43^{\circ} \mathrm{C}$ and another $23 \mathrm{~h}$ of incubation under normal conditions. For propofol treatment, cells at $70 \%$ confluence were grown in serum-free DMEM supplemented with $50 \mu \mathrm{M}$ propofol for $24 \mathrm{~h}$ under normal conditions. For $\mathrm{HS}+\mathrm{P}$, cells were treated with $50 \mu \mathrm{M}$ propofol followed by $1 \mathrm{~h}$ of heat stress at $43^{\circ} \mathrm{C}$ and $23 \mathrm{~h}$ of incubation under normal conditions. For LPS $+\mathrm{P}$, cells were treated with $1 \mu \mathrm{g} / \mathrm{mL}$ LPS and $50 \mu \mathrm{M}$ propofol and incubated for $24 \mathrm{~h}$ under normal conditions. For HS $+\mathrm{LPS}+\mathrm{P}$, cells were treated with $1 \mu \mathrm{g} / \mathrm{mL}$ LPS and $50 \mu \mathrm{M}$ propofol and incubated at $43^{\circ} \mathrm{C}$ for $1 \mathrm{~h}$ followed by $23 \mathrm{~h}$ of incubation under normal conditions.

\section{Detection of cell viability}

The MTT [3-(4,5-dimethylthiazol-2-yl)-2,5-diphenyltetrazolium bromide] method was used to detect cell viability after different treatments. After removal of the medium, $150 \mu \mathrm{L}$ MTT $(0.5 \mathrm{mg} / \mathrm{L})$ was added to the cells and then incubated for $4 \mathrm{~h}$. Subsequently, the supernatant was removed and $150 \mu \mathrm{L}$ dimethyl sulfoxide added, with shaking for $5 \mathrm{~min}$, until the crystals were fully dissolved. Absorbance (A) at $490 \mathrm{~nm}$ was measured for each well, and cell viability was calculated using the following equation: cell viability $=A_{\text {treatment }} / A_{\text {control }}$.

\section{Detection of apoptosis}

Double staining with annexin V-fluorescein isothyocyanate (FITC) and propidium iodide (PI) was used to detect apoptosis. The cells in each group were washed with phosphate-buffered saline twice and detached with EDTA-free trypsin. Subsequently, cells were resuspended in $500 \mu \mathrm{L}$ binding buffer and stained with $1 \mu \mathrm{L}$ annexin $\mathrm{V}$-FITC and $1 \mu \mathrm{L} \mathrm{PI}$. Apoptosis was detected using flow cytometry within $1 \mathrm{~h}$ in order to avoid false results. Apoptosis was calculated using the following equation: apoptosis rate $=$ number of apoptotic cells/(number of apoptotic cells + number of living cells) $\times 100 \%$.

\section{Statistical analysis}

All data were analyzed using the SPSS 16.0 software (IBM, USA). Quantitative data were reported as means $\pm S D$. All comparisons were conducted after homogeneity of variance $(P>0.05)$ was confirmed. Comparison between each group was performed using single factor analysis of variance (one-way ANOVA). Multiple comparisons among different groups were performed using a least-significant difference test or the Student-Newman-Keuls method. The Welch method was used for data with heterogeneity of variance, and the Dunnett T3 test was used for multiple comparisons. $\mathrm{P}<0.05$ was considered to be statistically significant.

\section{Results}

\section{Effect of heat stress and LPS on cell viability}

Cell viability in the HS, LPS, and combination groups was significantly lower than in the control group $(P<0.05)$. In addition, cell viability in the combination group was significantly lower than either HS or LPS groups 
$(P<0.05)$. There was no significant difference between the LPS and HS groups $(P>0.05)$. These results indicated that either heat stress or LPS can cause a certain degree of damage in IEC- 6 cells and a combination of these two treatments would produce a synergistic effect (Figure 1).

Effect of propofol on heat stress and combination of heat stress and LPS-induced reduction of cell viability

There was no significant difference between the $P$ group and the control group $(P=0.373)$ in cell viability. However, cell viability in the combination group was significantly higher than that in the HS group $(P=0.021)$. These results indicate that propofol does not affect cell growth, but plays a protective role in heat-stress-induced damage. Moreover, cell viability in the LPS $+\mathrm{P}$ group was significantly higher than that in the LPS group $(P<0.001)$. Cell viability in the HS + LPS + P group was significantly higher than that in the HS + LPS group $(P<0.001)$. These results indicate that propofol can protect cell damage caused by the combination of heat stress and LPS stimulation (Figure 2).

\section{Effect of heat stress and LPS on apoptosis}

There were significant differences in apoptotic rates among the control, HS, LPS, and LPS + HS groups $(P<0.001)$. Apoptotic rate in the LPS, HS, and HS + LPS groups was significantly higher than that in the control group $(P<0.001)$. Apoptotic rate in the HS + LPS group was also higher than that of the LPS or HS groups $(P<0.05)$, However, there was no significant difference between the LPS and HS groups. These results indicated that heat stress or LPS could increase apoptosis of IEC cells and the combination of these two treatments could produce a synergistic effect (Figure 3 ).

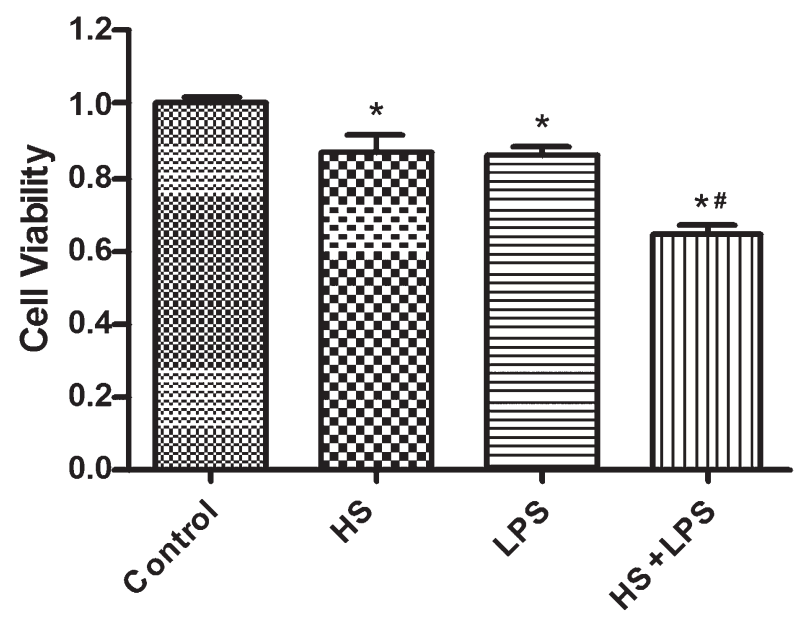

Figure 1. Effects of heat stress (HS) and lipopolysaccharide (LPS) on the cell viability of IEC-6 cells. Data are reported as means $\pm S D, n=6$. ${ }^{*} \mathrm{P}<0.05$ vs control, and ${ }^{\#} \mathrm{P}<0.05$ vs $\mathrm{HS}$ or LPS (one-way ANOVA).

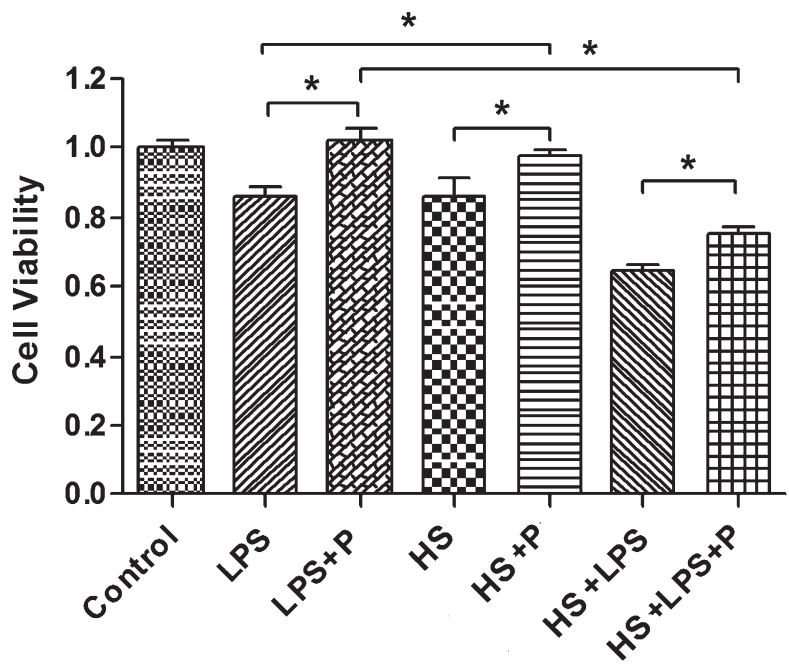

Figure 2. Effects of propofol (P) on the cell viability of IEC-6 cells after heat stress (HS), lipopolysaccharide (LPS), or a combination of HS and LPS treatment. The MTT [3-(4,5-dimethylthiazol-2yl)-2,5-diphenyltetrazolium bromide] method was used for evaluation. Data are reported as means $\pm S D, n=6$. ${ }^{*} P<0.05$, Student-Newman-Keuls test.

\section{Effect of propofol on heat stress and combination of heat stress and LPS-induced apoptosis}

Propofol treatment did not affect apoptotic rate. In addition, the apoptotic rate in the HS + P group was not significantly different from that in the HS group $(P>0.05)$. These results indicated that propofol treatment may have no significant effect on heat-stress-induced apoptosis. Apoptotic rate in the LPS + $\mathrm{P}$ group was significantly lower than that in the LPS group $(P=0.047)$. In addition, the

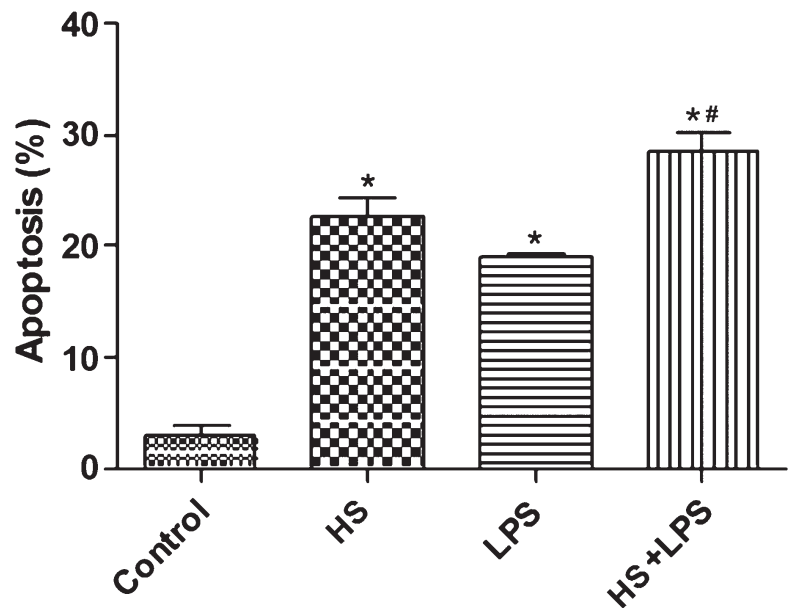

Figure 3. Effects of heat stress (HS) and lipopolysaccharide (LPS) on the apoptosis ratio of IEC-6 cells. Data are reported as means $\pm \mathrm{SD}, \mathrm{n}=6$. ${ }^{*} \mathrm{P}<0.01$ vs control, ${ }^{\#} \mathrm{P}<0.05$ vs LPS or HS (one-way ANOVA test). 
apoptotic rate in the HS + LPS + P group was significantly lower than that in the HS + LPS group $(P=0.011)$. These results indicate that treatment with propofol can reduce apoptosis caused by LPS or a combination of LPS and heat stress (Figure 4).

\section{Discussion}

The mechanism in heat-stress-induced multiple organ failure is not fully understood. The presence of endotoxemia and intestinal bleeding suggest that a change in intestinal epithelial permeability may play an important role in this process (21). Moseley et al. (22) suggested that most of the tight junctions in intestinal epithelial cells could open at $38.3^{\circ} \mathrm{C}$; and, when the temperature exceeded $41.5^{\circ} \mathrm{C}$, all the tight junctions would be opened, resulting in increased permeability to macromolecules. Early studies on heat stroke in animal models also showed that leakage of microorganism endotoxins from the intestine was increased after thermal damage in the intestinal mucosa (23). Lambert et al. (12) utilized the fluorescent molecule FITC-dextran to study the intestinal permeability of rats in different heat stress conditions, and histological analysis showed that the extent of the damage and permeability of the intestinal epithelia were associated with the degree of heat stress.

It could be predicted that, under heat-stress conditions, endotoxins, bacteria, and antibodies in the intestine were constantly translocated into the blood and lymph, which resulted in the release of various inflammatory

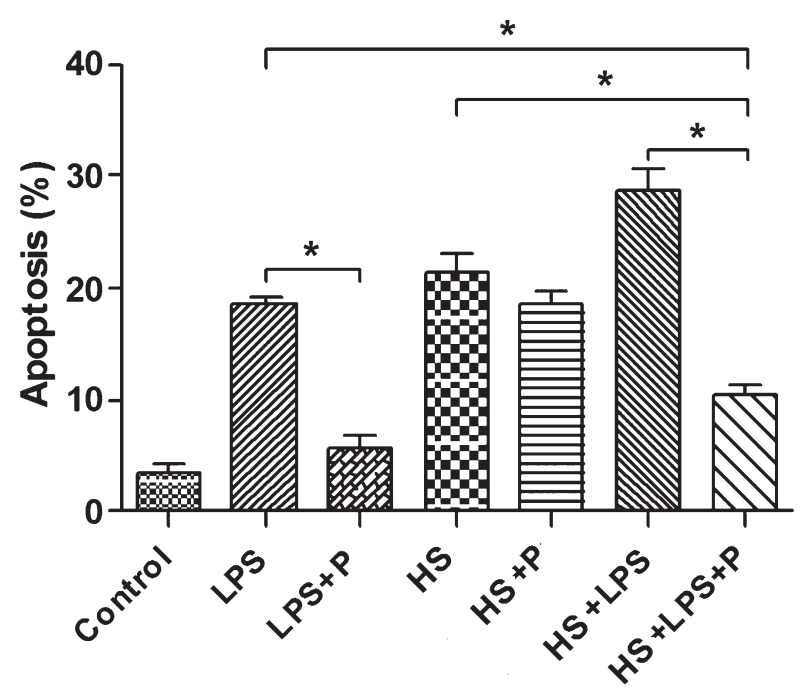

Figure 4. Effect of propofol $(P)$ on the apoptosis ratio of IEC-6 after heat stress (HS), lipopolysaccharide (LPS), or a combination of HS and LPS treatment. Double staining with annexin Vfluorescein isothyocyanate and propidium iodide was used to detect the effect of $P$ on the apoptosis ratio of IEC-6. Data are reported as means $\pm S D, n=6$. ${ }^{*} P<0.05$, Dunnett $T 3$ test. mediators and aggravation of the systemic inflammatory response syndrome (SIRS). Occurrence of SIRS further increased mucosal barrier damage, eventually leading to MODS (24). However, direct experimental evidence of epithelial cell damage in heat stress is not available.

In this study, we mimicked the micro-environment of intestinal epithelial cells under severe heat stress conditions and determined the cell viability and apoptotic rate. As predicted, heat stress or LPS stimulation could induce damage to intestinal epithelial cells (including early apoptosis and subsequent necrosis). In addition, a synergistic effect was produced when heat stress and LPS stimulation were combined. These results indicate that the unique environment during the process of intestinal heat stroke can induce multiple types of cell damage mediated by different molecules and signaling pathways. Our previous studies had shown that intestinal epithelial cells secreted significantly higher IL-8 under the condition of heat stress or LPS stimulation (25). However, further studies are needed to determine whether other cytokines or molecules are involved in this process.

Propofol plays an important role in anti-inflammation and organ protection. Thus, we determined the effect of propofol on heat-stress-induced cell injuries. Our results showed that propofol could alleviate the injuries caused by heat stress, LPS, or a combination of heat stress and LPS. There is additional evidence supporting the protective role of propofol in intestinal injury. Liu et al. (26) found that propofol attenuates intestinal ischemia-reperfusion $(\mathrm{l} / \mathrm{R})$-induced mucosal injury in an animal model. The response may be attributable to the antioxidant properties of propofol and the effects of inhibiting over-production of nitric oxide and in decreasing ET-1 levels (26). They also found that propofol pretreatment attenuates I/R-induced intestinal epithelial apoptosis (27). Sun et al. (28) found that propofol could inhibit traumatic brain injury that promoted a significant increment in plasma endotoxin, the L/M ratio, and intestinal levels of NF-kappa B, TNFalpha, and IL-6 in animal models. Vasileiou et al. (29) also found that anesthesia with propofol alleviated intestinal injury and efficiently prevented lipid oxidation following intestinal ischemia-reperfusion in Wistar rats. Yagmurdur's (30) results suggest that propofol as an anesthetic agent may prevent bacterial translocation by scavenging reactive oxygen species and inhibiting lipid peroxidation in an animal model of burn injury, and they also found that propofol could offer protection against apoptosis of enterocytes (31).

Interestingly, propofol can only inhibit LPS-induced intestinal apoptosis, but has no protective role in heatstress-induced apoptosis. We speculated that the organ protective effect of propofol was mainly associated with anti-inflammation and reduction of oxidative stress injury, which are similar to LPS-induced cell damage and quite different from heat-stress-induced physical damage. In 
Niederlechner's (32) study on glutamine's cytoprotective mechanism in heat-stressed intestinal epithelial cells, epidermal growth factor receptor and its associated signal transduction pathway molecules such as activated extracellular regulated protein kinases $1 / 2$ and decreased p38 mitogen-activated protein kinases signaling may play an important role, and provide a basis for future study. In conclusion, this study developed a model that can mimic the intestinal heat stress environment, demonstrated its effects on intestinal epithelial cell damage, and indicated

\section{References}

1. Bouchama A, Knochel JP. Heat stroke. N Engl J Med 2002; 346: 1978-1988, doi: 10.1056/NEJMra011089.

2. al-Mashhadani SA, Gader AG, al Harthi SS, Kangav D, Shaheen FA, Bogus F. The coagulopathy of heat stroke: alterations in coagulation and fibrinolysis in heat stroke patients during the pilgrimage (Haj) to Makkah. Blood Coagul Fibrinolysis 1994; 5: 731-736, doi: 10.1097/ 00001721-199410000-00009.

3. Dematte JE, O'Mara K, Buescher J, Whitney CG, Forsythe $\mathrm{S}$, McNamee T, et al. Near-fatal heat stroke during the 1995 heat wave in Chicago. Ann Intern Med 1998; 129: 173-181, doi: 10.7326/0003-4819-129-3-199808010-00001.

4. Gathiram P, Wells MT, Brock-Utne JG, Gaffin SL. Antilipopolysaccharide improves survival in primates subjected to heat stroke. Circ Shock 1987; 23: 157-164.

5. Gathiram P, Wells MT, Brock-Utne JG, Gaffin SL. Prophylactic corticosteroid increases survival in experimental heat stroke in primates. Aviat Space Environ Med 1988; 59: 352-355.

6. Turnbull IR, Javadi P, Buchman TG, Hotchkiss RS, Karl IE, Coopersmith CM. Antibiotics improve survival in sepsis independent of injury severity but do not change mortality in mice with markedly elevated interleukin 6 levels. Shock 2004; 21: 121-125, doi: 10.1097/01.shk.0000108399.56565.e7.

7. Gianotti L, Braga M, Vaiani R, Almondo F, Di Carlo V. Experimental gut-derived endotoxaemia and bacteraemia are reduced by systemic administration of monoclonal antiLPS antibodies. Burns 1996; 22: 120-124, doi: 10.1016/ 0305-4179(95)00100-X.

8. Sittig K, Deitch EA. Effect of bacteremia on mortality after thermal injury. Arch Surg 1988; 123: 1367-1370, doi: 10.1001/archsurg.1988.01400350081012.

9. Gathiram P, Wells MT, Brock-Utne JG, Wessels BC, Gaffin $\mathrm{SL}$. Oral administered nonabsorbable antibiotics prevent endotoxemia in primates following intestinal ischemia. $J$ Surg Res 1988; 45: 187-193, doi: 10.1016/0022-4804(88)90064-9.

10. Marshall JC. The International Sepsis Forum's controversies in sepsis: how will sepsis be treated in 2051? Crit Care 2002; 6: 465-467, doi: 10.1186/cc1539.

11. Hall DM, Buettner GR, Oberley LW, Xu L, Matthes RD, Gisolfi CV. Mechanisms of circulatory and intestinal barrier dysfunction during whole body hyperthermia. Am J Physiol Heart Circ Physiol 2001; 280: H509-H521.

12. Lambert GP, Gisolfi CV, Berg DJ, Moseley PL, Oberley LW, Kregel KC. Selected contribution: hyperthermia-induced intestinal permeability and the role of oxidative and that propofol could be used as a therapeutic drug for the treatment of heat-stress-induced intestinal injuries.

\section{Acknowledgments}

Research supported by grants from National Natural Science Foundation of China (\#81071529, \#81101467) and Guangdong Province Natural Science Foundation of China (\#10151001002000001, \#10451001002005047, \#S2012010008120).

nitrosative stress. J Appl Physiol 2002; 92: 1750-1761.

13. Bouchama A, Roberts G, Al Mohanna F, El-Sayed R, Lach $B$, Chollet-Martin S, et al. Inflammatory, hemostatic, and clinical changes in a baboon experimental model for heatstroke. J Appl Physiol 2005; 98: 697-705, doi: 10.1152/japplphysiol.00461.2004.

14. Liu Z, Liu JH, Liu Y, Tang Y, Meng F, Sun X, et al. Proteomic analysis and identification of intestinal FBP as a predictor of gut dysfunction during heatstroke in mice. J Surg Res 2012; 173: 332-340, doi: 10.1016/j.jss.2010.09.043.

15. Liu Z, Sun $X$, Tang J, Tang $Y$, Tong $H$, Wen $Q$, et al. Intestinal inflammation and tissue injury in response to heat stress and cooling treatment in mice. Mol Med Rep 2011; 4: 437-443, doi: 10.3892/mmr.2011.435.

16. Gonzalez-Correa JA, Cruz-Andreotti E, Arrebola MM, Lopez-Villodres JA, Jodar M, De La Cruz JP. Effects of propofol on the leukocyte nitric oxide pathway: in vitro and ex vivo studies in surgical patients. Naunyn Schmiedebergs Arch Pharmacol 2008; 376: 331-339, doi: 10.1007/s00210007-0220-4.

17. Tang J, Chen X, Tu W, Guo Y, Zhao Z, Xue Q, et al. Propofol inhibits the activation of p38 through up-regulating the expression of annexin A1 to exert its anti-inflammation effect. PLoS One 2011; 6: e27890, doi: 10.1371/journal.pone. 0027890

18. Aoki H, Mizobe T, Nozuchi S, Hiramatsu N. In vivo and in vitro studies of the inhibitory effect of propofol on human platelet aggregation. Anesthesiology 1998; 88: 362-370, doi: 10.1097/00000542-199802000-00015.

19. Tang J, Sun Y, Wu WK, Zhong T, Liu Y, Xiao J, et al. Propofol lowers serum PF4 level and partially corrects hypercoagulopathy in endotoxemic rats. Biochim Biophys Acta 2010; 1804: 1895-1901, doi: 10.1016/j.bbapap.2010.06.018

20. Yamada H, Kawano T, Tanaka K, Yasui S, Mawatari K, Takahashi A, et al. Effects of intracellular MgADP and acidification on the inhibition of cardiac sarcolemmal ATPsensitive potassium channels by propofol. J Anesth 2007; 21: 472-479, doi: 10.1007/s00540-007-0551-9.

21. Lambert GP. Role of gastrointestinal permeability in exertional heatstroke. Exerc Sport Sci Rev 2004; 32: 185-190, doi: 10.1097/00003677-200410000-00011.

22. Moseley PL, Gapen C, Wallen ES, Walter ME, Peterson MW. Thermal stress induces epithelial permeability. Am J Physiol 1994; 267: C425-C434.

23. Gathiram P, Gaffin SL, Brock-Utne JG, Wells MT. Time course of endotoxemia and cardiovascular changes in 
heat-stressed primates. Aviat Space Environ Med 1987; 58 : 1071-1074.

24. Zhou DY. Bacterial and endotoxin translocation: prevention and treatment. Chin J Gastro 2003; 8: 3-5.

25. Tang LQ, Yuan FF, Liu YW, Xu QL, Su L, Liu ZF. Effects of lipopolysaccharide combined with heat stress on the expression and secretion of cytokines released from human intestinal epithelial cells SW480. Infect Inflam Repair 2012; 13: 6-9.

26. Liu KX, Rinne T, He W, Wang F, Xia Z. Propofol attenuates intestinal mucosa injury induced by intestinal ischemiareperfusion in the rat. Can $J$ Anaesth 2007; 54: 366-374, doi: $10.1007 / B F 03022659$.

27. Liu KX, Chen SQ, Huang WQ, Li YS, Irwin MG, Xia Z. Propofol pretreatment reduces ceramide production and attenuates intestinal mucosal apoptosis induced by intestinal ischemia/reperfusion in rats. Anesth Analg 2008; 107: 1884-1891, doi: 10.1213/ane.0b013e3181884bbf.

28. Sun J, Wang L, Shen J, Wang Z, Qian Y. Effect of propofol on mucous permeability and inflammatory mediators expression in the intestine following traumatic brain injury in rats. Cytokine 2007; 40: 151-156, doi: 10.1016/ j.cyto.2007.09.003.

29. Vasileiou I, Kalimeris K, Nomikos T, Xanthopoulou MN, Perrea D, Agrogiannis G, et al. Propofol prevents lung injury following intestinal ischemia-reperfusion. J Surg Res 2012; 172: 146-152, doi: 10.1016/j.jss.2010.07.034.

30. Yagmurdur H, Akca G, Aksoy M, Arslan M, Baltaci B, Dikmen $B$. The effects of ketamine and propofol on bacterial translocation in rats after burn injury. Acta Anaesthesiol Scand 2005; 49: 177-182, doi: 10.1111/j.1399-6576.2004.00560.x.

31. Yagmurdur H, Aksoy M, Arslan M, Baltaci B. The effects of propofol and ketamine on gut mucosal epithelial apoptosis in rats after burn injury. Eur J Anaesthesiol 2007; 24: 46-52.

32. Niederlechner S, Baird C, Petrie B, Wischmeyer E, Wischmeyer PE. Epidermal growth factor receptor expression and signaling are essential in glutamine's cytoprotective mechanism in heat-stressed intestinal epithelial-6 cells. Am J Physiol Gastrointest Liver Physiol 2013; 304: G543G552, doi: 10.1152/ajpgi.00418.2012. 